\title{
Designing a Platform for Participatory Urbanism: Transforming Dialogue into Action in Underserved Communities
}

\author{
Leonardo Giusti, Amelia Schladow, Amar Boghani, Steve Pomeroy, \\ Nicholas Wallen, and Federico Casalegno \\ MIT Mobile Experience Lab, 20s Ames Street, Cambridge 02139, MA \\ \{lgiusti, schladow, amarkb, spomeroy, nwallen, casalegno\}@mit.edu
}

\begin{abstract}
Participatory urbanism platforms must balance stakeholder needs to both empower citizens and exact change from the local authority. While many platforms can trigger discussion, changes will only be achieved through successful collaborative efforts. This paper outlines the challenges and opportunities of designing for participatory urbanism, drawing on a case study completed with UNICEF and underserved communities in Rio de Janeiro, Brazil. Our design approach helped to generate physical changes in the community infrastructure, and the beginnings of behavioral changes for community residents.
\end{abstract}

Keywords: Participatory urbanism, civic media, location-based platforms.

\section{Introduction}

In this paper we investigate how participatory platforms, mediated by mobile and web-based technologies, provoke new methods and possibilities for individual citizens to become actively involved in their neighborhood, city, and urban landscape. In particular, we address how these platforms can support participatory urbanism in underserved and low-income communities, discussing challenges and opportunities.

The discussion presents a case study: UNICEF - Youth Mapping in Rio de Janeiro [1]. The project aimed to empower youth in the favelas of Rio de Janeiro with digital mapping technology for reporting environmental and structural hazards. A specialized version of the Open Locast [2, 3, 4] web and mobile platform (UNICEF GIS) was designed to fit the specific constraints of the local context. With the help of UNICEF and the involvement of local authorities, we organized a series of workshops to train 111 youths to use the technology. More than 300 reports were collected and the local government has planned and implemented several interventions to solve the problems reported by these local residents.

The presentation of the case study and its results helps to articulate a discussion about the design of participatory platforms and the challenges related to their adoption, sustainability, and impact in developing communities. Specifically, we discuss 
our contribution to one of the challenges identified by Ho in "Human-Computer Interaction for Development: The Past, Present, and Future" [5]: supporting an ecosystem around affordable computing. In this paper, we advocate a design approach that integrates the development of resilient and affordable technological systems with a social and cultural strategy, which includes the early involvement of the local authorities and community in activities. In particular, we discuss the importance of thoughtfully balancing the different voices involved in the discussion to both empower local residents, and activate the local municipality in taking a course of action.

This approach helped to successfully implement a media platform for participatory urbanism. In addition to concrete results documented by improvements to the local environment, user interviews showed how the project sparked a cultural shift, encouraging self-reflection and a sense of commitment toward the quality of the urban environment.

\section{Related Works}

A number of recent projects $[6,7,8]$ show the ways in which mobile media is valuable for enhancing information and knowledge exchange in developing communities. According to Ho et al. [5], a key challenge of HCI for developing countries is creating an ecosystem around affordable computing. He stressed the importance of replicable, low-cost approaches and hardware that can be appropriated and adopted by community-based organizations with minimal requirements for external support.

However, designing for underserved communities requires significantly more than just technological considerations. As outlined by Dearden et al [6], the form of new technologies represents physical capital for the designer to work with, but attention must be paid to human capital, social capital, financial capital, and the transforming structures and processes (i.e. organizational situations in the locality where the technology is intended to be used). Furthermore, they mention the importance of planning the way external agents will interact with local people and communities, since the goal of intervention is to work with locals to envision, create, and adopt sustainable systems that ultimately empower the locality.

This overarching framework provides a starting point for socio-technological considerations in the design of civic platforms for developing communities. Civic media platforms can enable community engagement and introduce multiple points of view into urban discussion. However, a number of challenges emerge when they are applied to participatory urbanism in addition to the challenges implicit in participatory practices in general.

Historically, participatory practices in urbanism can be traced to user-centric visions for architecture in the 1960s. Of particular interest is the work of Yona Friedman, an architect who advocated for architecture to remain a framework for further development by the inhabitant [9]. The notion of the open framework is also visible in 
the work of Cedric Price et al. [10], an architect who argued for engaging inhabitants as co-designers through temporary architecture and the integration of technology. However, in engaging ideas of user-participation in urbanism, we should also consider potential drawbacks. In Nightmare of Participation [11], Markus Miessen introduced his series of essays by challenging the current state of such practices. "Both historically and in terms of political agency, participation is often read through romantic notions of negotiation, inclusion, and democratic decision making. However, it is precisely this often questioned mode of inclusion that does not produce significant results," as the voices of the needy are frequently drowned out by the concept of the majority. The risk, as Miessen points out is that the idea of participation can be used as a strategy for consensus and political control: "too often it becomes an expedient method of placation rather than a real process of transformation" [11].

The debate about participatory urbanism in architecture highlights fundamental aspects that are often underestimated in the design of media platforms for civic engagement. The effectiveness of a particular platform correlates with its ability to inform and support the transformation of dialogues into actions: as a consequence, any conversation is inherently somewhat political. In order to make effective decisions and direct interventions a mechanism for selecting, filtering, and prioritizing content needs to be instated; furthermore, a local municipality or governing body has to be involved as a stakeholder from the beginning of the process. A civic media platform is a complex socio-technical system where the power relationship between the involved actors needs to be carefully articulated and specific strategies of engagement, negotiation, and conflict resolution should be designed.

\section{$3 \quad$ Youth Mapping Project}

\subsection{Context}

Rio de Janeiro is vulnerable to floods and landslides, natural disasters that are expected to increase with climate change. The city's favelas are largely situated along mountainsides, and are already prone to both disasters and socio-environmental risks. In response, UNICEF, with the support of the Municipality of Rio, the Municipal Secretariat of Health and Civil Defense, and Centro de Promoção da Saúde (CEDAPS), decided to start a project in which local adolescents are mobilized to monitor, identify and prioritize social and environmental risks in their community.

In particular, the project had two main design objectives: (1) strengthen participatory governance, and empower local residents to directly improve their local communities; (2) help the local government to be better informed about social and structural conditions, and plan future interventions. The local context posed several technological and social challenges: (1) limited technological infrastructure, in particular slow or absent 3G connection; (2) low penetration of smartphones; (3) social resistance to the adoption of services and products developed outside the local community; (4) lack of faith in real change. 


\subsection{Design Approach}

The UNICEF GIS platform is a youth-led civic media platform composed of a mobile and a web application, designed to engage residents in photo-documenting social and environmental risks in their communities (see section 3.3).

However, the design of the platform was not limited to the technological features; it also encompassed a social and cultural strategy. To foster the adoption of the system and the active participation of the local population, we designed a mediation framework that is both technological (to drive specific actions) and political. A series of workshops (see section 3.4) were organized to instruct youths on the use of the technology, to mobilize them toward environmental and social risks, and to involve local authorities and decision makers in the process. UNICEF played a central role in this process; its local connections were critical to identifying the human, social, and financial capital specific to the territory and to organize the participation process.

\subsection{Technology}

We worked with UNICEF to build upon the Open Locast [2, 3, 4] platform and customize it for digital mapping in Rio de Janeiro (see fig. 1). UNICEF's knowledge of the community and their experience working with youth helped to contextualize the implementation of Open Locast. The Open Locast platform for this project consisted of a mobile application to capture photos and text, and a website to illustrate and discuss the geo-located collection of media. Visualization for both the mobile and web components were simplified and made more approachable for youth. Finally, maps were organized around themes (e.g. erosion, sanitation, power line problems, social spaces, etc.) to improve organization and comprehensibility for the participants. Particular attention was paid to the creation of a resilient technological infrastructure to cope with connectivity limitations. The Open Locast platform saves all generated content so that it can be automatically uploaded when the connection improves. Furthermore, media content could also be created with other devices (e.g. cameras), and then uploaded using the web application. This provided a series of different opportunities in a context where the penetration of devices is low and presents serious limitations.

Open Locast. Open Locast is a location-based media platform created by the Mobile Experience Lab. It is an integrated platform that combines mobile and web tools to help users create individual and collective narratives, share content, and build local
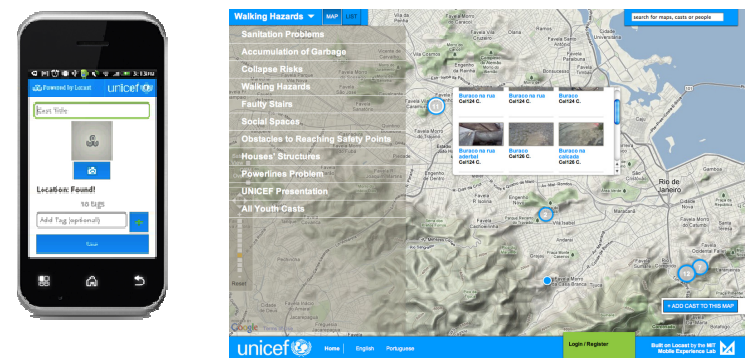

Fig. 1. A screenshot of the mobile application (left) and the website (right) 
conversations. Open Locast serves as a tool for horizontal reporting, that is, entirely user-generated content, populated as a centralized space for photographs and videos generated by users, citizens, or specific workshop participants. As it leverages a usergenerated tagging system to classify content and add semantic relations between casts, it allows for both user-generated and user-organized content - creating and building an archive solely based on the content present in real-time with location [4]. The Open Locast platform is made up of three components: the Web Interface, the Core (backend and API), and the Mobile application (Android). The Open Locast Core is in Django, which includes GeoDjango to incorporate a geographic web framework enabling powerful storage, querying, and geographic information manipulation. The core features an extensive network-centric API, RESTful and JSON, which allows data stored in Open Locast to be easily accessed and manipulated, allowing a wide- range of visualizations, statistical analyses, and user interfaces. Open Locast Web, which runs through Django, serves as the program's web presence and interface. All map-based interactions and visualizations are handled by OpenLayers a JavaScript library for displaying map data. It currently functions on Android platforms, and communicates with the Core using its API. The data is stored in an SQLite database based on the Android Content Provider framework.

\subsection{Workshops and Activities}

The Youth Mapping project involved a group of 111 adolescent (from 11 to 18), community thought-leaders, and local authorities in mapping environmental risks in target communities. The project implementation was carried out in a two-step approach: an initial session to train key stakeholders (see fig. 2 on the left) and secondary workshops with local youths for content generation (see fig. 2 on the right).
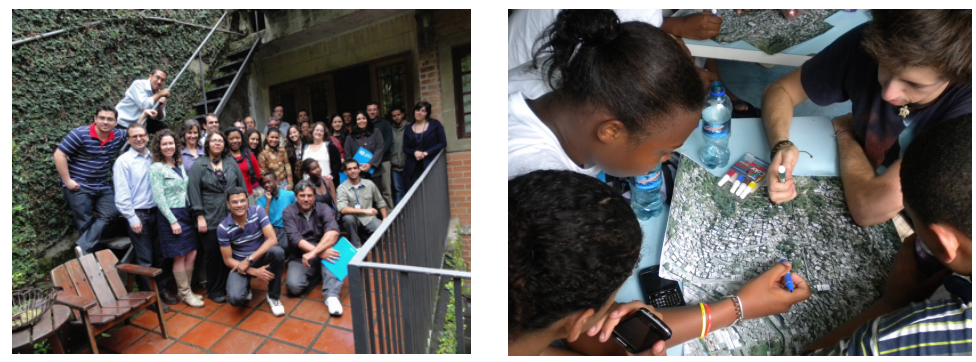

Fig. 2. Workshop participant training session (left), youths at workshop in Rio de Janeiro (right)

In preparation for a series of workshops, a "trainer of trainers" session was scheduled with key stakeholders: UNICEF, the Public Laboratory for Open Technology and Science, and a selection of Rio community stakeholders, including local NGOs, technical professionals from the Municipal Departments of Health and the Environment, local community members, and adolescent peer mentors. The training session provided space to share knowledge and introduce the technology to the community.

After this initial session, workshops were collaboratively planned. Five 5-day workshops were organized in 5 underserved communities of Rio de Janeiro (Morro 
dos Prazeres, Morro dos Macacos, Morro do Borel, Morro do Urubu and Rocinha). Each workshop hosted approximately 25 adolescents as well as the aforementioned community leaders, NGOs, and other local authorities. Local experts instructed youth on how to recognize specific potential hazards. For example, mudslides are a major concern in these communities and thus, the youth were instructed to take pictures of certain erosion patterns and dangerous overhangs. The youth were provided phones and guided in using the customized Open Locast platform, and then worked with community organizers and UNICEF to create real-time portraits of their community.

\subsection{Assessment}

Altogether, the youth generated about 300 casts, which are currently mapped and used as a reference [12]. The following picture (see fig. 3) documents the results of the project, showing specific intervention informed by the mapping activities and conducted by the local authorities.

To assess the workshops, youth and instructors were interviewed according to prepared questionnaires. We interviewed 6 youths ( 3 males and 3 females) and 2 instructors. Technically, the platform functioned well. At times, a slow $3 \mathrm{G}$ connection prevented casts from uploading properly, but the information architecture of the Open Locast platform was designed to cope with this issue.
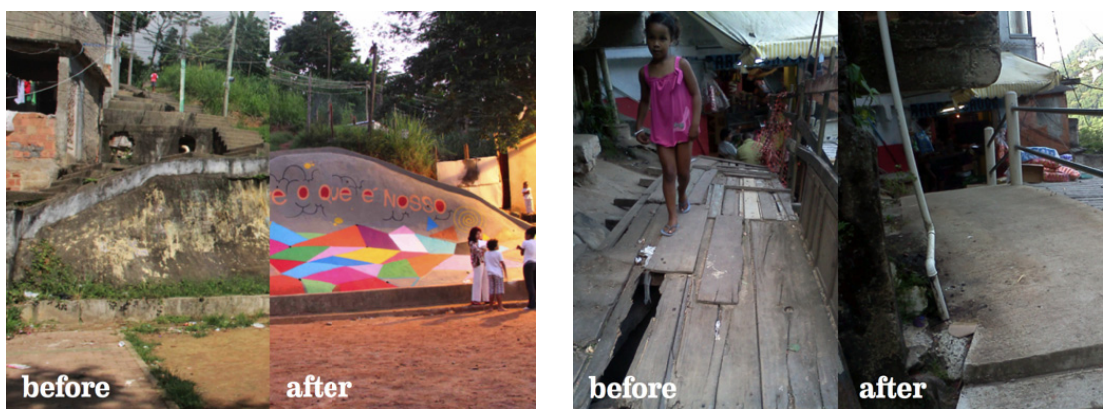

Fig. 3. Improvements made to communities, as informed by the Youth Mapping project

In addition to creating this resource, the workshops seemed to impact participants' perspective and behaviors; many of the youth were inured to the state of their locale, but capturing specific risks and unpleasant elements helped them learn to expect more from their community. Emboldened, the youth began to see how they could have a voice in local policy. Involvement in the mapping activity helped youths to look at their community in a different way, as exemplified by the following interview responses: "I could see things I had not seen before. Thanks to this activity I realized there is a lot of garbage all around our place", "I got to know places that I didn't know before, and I saw problems that I hadn't noticed before". The youths began to identify a social geography "We realized that the reality of those of us who live in the bottom part of the Morro is much better than that of those who live in the upper parts of it".

More importantly, youths stated an intention to change their habits: "before I was always throwing garbage anywhere, now I've realized that's something bad for the community and I'll try to change it". Yet, as one of the teacher pointed out: "a few 
students told me they now felt bad about throwing trash on the ground and would try to do it less. At the same time, I still observed them throwing a water bottle on the ground after our conversation." However, the intention to change habits shows an opportunity to build upon and the potential for behavioral shifts.

\section{$4 \quad$ Lessons Learned}

Following the Rio de Janeiro experience, the Youth Mapping project was successfully deployed in Haiti in July 2012 [13]. UNICEF adopted the same technological platform (Open Locast) and a similar cultural strategy. In partnership with two local organizations, GHESKIO and the National Office against Violence (ONAVC), UNICEF took on the challenge of identifying places where adolescents and young people are at increased risk of contracting HIV. We are now considering extending the project to 10 cities in Brazil. The interest in continuing the project testifies its effectiveness and impact. In particular, the project was a success in building:

Participation. The Youth Mapping project helped community members to document needed improvements, allowing residents to directly contribute to the amelioration of their neighborhoods;

Governance. This tool for empowerment can provide local governments with constant feedback on problems in underserved areas. The initiative is responsible for real change; as a result of photos and comments from the workshops, repairs have already been made;

Education. Through a hands-on investigation, the youths were encouraged to think critically about how maps and new digital tools can inform community discourse on economic, environmental, and social sustainability.

We strongly believe that the success of this project relies on the design approach we adopted. As previously discussed, we decided to integrate the design of the technological platform with a social and cultural strategy. The role played by UNICEF as a mediator was crucial for the success of the project. UNICEF's long-term presence in the territory, ability to build trust in the communities, and power in activating local resources were fundamental to the adoption of the technology, and to promote a behavioral and cultural change.

The underlying challenge of designing platforms for participatory urbanism is the transformation of dialogue into action, which requires harmony between stakeholder perspectives. Local authorities need to be included in the design and implementation of platforms from the earliest stages. They help to engage the local community and cause real change. And yet, since local authorities are in a position of strong power, their voice in decision-making processes can be louder than the public and they have greater potential to set the final agenda. It is important to mediate the role of local authorities and strategically balance their involvement with that of local residents. This is particularly true in developing communities, where power dynamics and access to resources can be especially skewed. Our approach in assuaging this challenge was an intermediary group of thought-leaders, community activists, and young mentors who mobilize locals and empower them from the ground up. In this way, the public holds local authorities accountable and sets its own goals for the community. 
Our contribution to the challenge identified by Ho - supporting an ecosystem around affordable computing - shows how considerations should go beyond technology to encompass social and cultural capital. Specifically, in the context of designing a participatory urbanism platform for underserved communities, we have illustrated the need to include local authorities without compromising the voices of local residents. Our approach of using local leaders as mediators, helped to manage diverse stakeholder needs. As a result of a successful collaboration, we observed the beginnings of a behavioral shift and the potential for sustainable impact in the community.

\section{References}

1. http://www.unicef-gis.org/

2. Arslan, P., Brunnberg, L., Casalegno, F., Schladow, Z.: Locast H2flow: creative learning tool for participatory urbanism. In: Proceedings of the Second Conference on Creativity and Innovation in Design, pp. 267-270. ACM (October 2011)

3. Giusti, L., Pollini, A., Brunnberg, L., Casalegno, F.: En Plein Air: A Mobile Learning Approach for Sustainability Education in the Wild. International Journal of Mobile Human Computer Interaction (IJMHCI) 4(2), 44-58 (2012)

4. Chernyakova, I., Villeré, M., Casalegno, F., Giusti, L., Schladow, Z.: Civic Media Platforms and Participatory Urbanism: A Critical Reflection. International Journal of Architectural Computing 10(2), 253-274 (2012)

5. Ho, M.R., Smyth, T.N., Kam, M., Dearden, A.: Human-computer interaction for development: The past, present, and future. Information Technologies \& International Development 5(4), 1 (2009)

6. Dearden, A., Rizvi, S.M.H.: A deeply embedded sociotechnical strategy for designing ICT for development. International Journal of Sociotechnology and Knowledge Development (IJSKD) 1(4), 52-70 (2009)

7. Parikh, T.S., Lazowska, E.D.: Designing an architecture for delivering mobile information services to the rural developing world. In: Proceedings of the 15th International Conference on World Wide Web, pp. 791-800. ACM (May 2006)

8. Gitau, S., Marsden, G., Donner, J.: After access: challenges facing mobile-only internet users in the developing world. In: Proceedings of the 28th International Conference on Human Factors in Computing Systems, pp. 2603-2606. ACM (April 2010)

9. Friedman, Y.: L'architecture mobile: vers une cité conçue par ses habitants, vol. 5. Casterman (1970)

10. Banham, R., Barker, P., Hall, P., Price, C.: Non-plan: an experiment in freedom. New Society 20, 435-443 (1969)

11. Miessen, M.: The nightmare of participation. Sternberg Press (2010)

12. http://rio.unicef-gis.org/

13. http://pap.unicef-gis.org/ 